\title{
BMJ Open Cross-sectional analysis of sleep- promoting and wake-promoting drug use on health, fatigue-related error, and near-crashes in police officers
}

\author{
Rowan P Ogeil, ${ }^{1,2,3,4}$ Laura K Barger, ${ }^{1,2}$ Steven W Lockley, ${ }^{1,2,5}$ Conor S O'Brien, ${ }^{1}$ \\ Jason P Sullivan, ${ }^{1}$ Salim Qadri, ${ }^{1}$ Dan I Lubman, ${ }^{3,4}$ Charles A Czeisler, ${ }^{1,2}$ \\ Shantha M W Rajaratnam ${ }^{1,2,5}$
}

To cite: Ogeil RP, Barger LK, Lockley SW, et al. Crosssectional analysis of sleeppromoting and wake-promoting drug use on health, fatiguerelated error, and near-crashes in police officers. BMJ Open 2018;8:e022041. doi:10.1136/ bmjopen-2018-022041

- Prepublication history and additional material for this paper are available online. To view please visit the journal (http:// dx.doi.org/10.1136/bmjopen2018-022041).

Received 31 January 2018 Revised 2 July 2018 Accepted 31 July 2018

Check for updates

(c) Author(s) (or their employer(s)) 2018. Re-use permitted under CC BY-NC. No commercial re-use. See rights and permissions. Published by BMJ.

${ }^{1}$ Division of Sleep and Circadian Disorders, Departments of Medicine and Neurology, Brigham and Women's Hospital, Boston, Massachusetts, USA

${ }^{2}$ Division of Sleep Medicine, Harvard Medical School, Boston, Massachusetts, USA

${ }^{3}$ Eastern Health Clinical School, Monash University, Melbourne, Victoria, Australia

${ }^{4}$ Turning Point, Eastern Health, Richmond, Victoria, Australia

${ }^{5}$ Monash Institute of Cognitive and Clinical Neurosciences and School of Psychological Sciences, Monash University, Clayton, Victoria, Australia

Correspondence to

Dr Rowan P Ogeil;

rowan.ogeil@monash.edu

\section{ABSTRACT}

Objectives To examine sleep-promoting and wakepromoting drug use in police officers and associations between their use and health (excessive sleepiness, stress and burnout), performance (fatigue-related errors) and safety (near-crashes) outcomes, both alone and in combination with night-shift work.

Design Cross-sectional survey.

Setting Police officers from North America completed the survey either online or via paper/pencil at a police station.

Participants 4957 police participated, 3693 online (91.9\%, participation rate) and 1264 onsite (cooperation rate $63.1 \%$ ).

Main outcome measures Sleep-promoting and wakepromoting drug use, excessive sleepiness, near-crash motor vehicle crashes, dozing while driving, fatigue errors, stress and burnout.

Results Over the past month, $20 \%$ of police officers reported using sleep-promoting drugs and drugs causing sleepiness, while wake-promoting agents were used by $28 \%$ of police (5\% used wake-promoting drugs, $23 \%$ used high levels of caffeine and $4 \%$ smoked to stay awake). Use of sleep-promoting drugs was associated with increased near-crashes $(0 \mathrm{R}=1.61 ; 95 \% \mathrm{Cl} 1.21$ to 2.13$)$, fatigue-related errors $(\mathrm{OR}=1.75 ; 95 \% \mathrm{Cl} 1.32$ to 2.79$)$, higher stress $(0 \mathrm{R}=1.41 ; 95 \% \mathrm{Cl} 1.10$ to 1.82$)$, and higher burnout ( $\mathrm{OR}=1.83 ; 95 \% \mathrm{Cl} 1.40$ to 2.38$)$. Wake-promoting drug use, high caffeine and smoking to stay awake were associated with increased odds of a fatigue-related error, stress and burnout (ORs ranging from 1.68 to 2.56). Caffeine consumption was common, and while smoking was not, of those participants who did smoke, one-in-three did so to remain awake. Night-shift work was associated with independent increases in excessive sleepiness, nearcrashes and fatigue-related errors. Interactions between night-shift work and wake-promoting drug use were also found for excessive sleepiness.

Conclusions Police who use sleep-promoting and wakepromoting drugs, especially when working night shifts, are most vulnerable to adverse health, performance and safety outcomes. Future research should examine temporal relationships between shift work, drug use and adverse outcomes, in order to develop optimal alertness management strategies.
Strengths and limitations of this study

- Examines the contribution of both use of sleep-promoting and wake-promoting drugs and shift schedules on health, performance and safety outcomes.

- Data were obtained from a large sample of North American police officers.

- Self-assessment of outcome measures was used, which may be subject to a bias not to report.

- The retrospective nature of the survey may have been affected by recall or social desirability bias.

\section{INTRODUCTION}

Sleep problems adversely impact the physical and mental health of individuals and place a high economic and healthcare burden on the community. ${ }^{1}$ Poorer health outcomes among those who work non-standard shifts include an increased prevalence of chronic sleep disorders including excessive daytime sleepiness, mental health disturbance (stress and burnout), cardiovascular disease and diabetes. $^{2}$

Shift-work disorder is characterised by insomnia and/or excessive daytime sleepiness associated with work schedules. ${ }^{3}$ Between $8 \%$ and $14 \%$ of shift workers meet the clinical criteria for a diagnosis of shift-work disorder, with rates as high as $26 \%$ reported in those working rotating shifts. ${ }^{2}$ The incidence of shift-work disorder is likely underestimated, however, given that the symptoms that define the disorder are common to many sleep disorders, and most shift workers will experience some adverse consequences as a result of opposing circadian physiology to sleep at night and to be awake during the day. ${ }^{2}$ As an occupational group, police provide services 24 hours a day, with officers required to work overnight shifts. Shift-work disorder in both police and other professionals is associated 
with adverse consequences including an increased propensity for work-related errors, decrements in performance and increase incidence of motor vehicle crashes or near-crashes, which collectively negatively impact both individual officers and the community. ${ }^{34}$

The majority of shift workers do not adapt to the shifted sleep-wake schedule required for their work, ${ }^{5}$ and our understanding of those workers who may be more vulnerable or resistant to shift-work disorder is limited. ${ }^{6}$ Circadian misalignment between internally driven physiological processes and the light-dark cycle has been proposed as the mechanism that underlies poorer physical and mental health observed in shift workers. ${ }^{7}$ Kalmbach $e t a l^{8}$ reported that those who develop shift-work disorder report greater levels of anxiety and depression compared with shift workers who do not. These negative effects were further compounded in shift workers with circadian systems that were slower to adapt to changes associated with work shifts, suggesting that while the biological clock has difficulty adapting to the demands imposed by shift work, there are likely trait and state characteristics of individuals that are associated with greater impairment or resilience to health and performance effects following night-shift work.

Hitherto, research examining shift schedules and effects on health and performance outcomes has generally not considered the use of sleep-promoting and wake-promoting drugs. While 1 in 10 adults in the general population have used alcohol as a sleep aid, recent data suggest higher rates of consumption in shift workers with one in six consuming alcohol to help initiate sleep between shifts. ${ }^{9}$ Indeed, following prescription sleep medications (eg, benzodiazepines), alcohol is also commonly used as sleeping aid by shift workers. ${ }^{10}$ High alcohol or continued use of prescription sleeping aids is of concern given that their long-term use is associated with poor health and public health outcomes. ${ }^{11}{ }^{12}$ For example, Roche et al ${ }^{13}$ reported that high-risk drinkers are 22 times more likely than low-risk drinkers to be absent from work due to alcohol use, placing a large burden on the economy due to lost productivity.

Common wake-promoting medications used by shift workers include freely available stimulants (eg, caffeine and nicotine), ${ }^{14}$ in addition to medication obtained via prescription, over-the-counter or as a supplement. A Cochrane review that examined pharmacological product efficacy for shift-work disorder found mixed to limited efficacy of wake-promoting agents including modafinil and caffeine. ${ }^{15}$ As with sleep-promoting medication, there may be negative consequences that accompany continued use of stimulants. For example, reliance on caffeine has been associated with poorer sleep quality, increased levels of daytime dysfunction and increased levels of night time disturbance. In contrast, nicotine dependence has been associated with poorer sleep quality and increased use of sleep medication and sleep disturbances. ${ }^{14}$

This study investigated the use of the sleep-promoting and wake-promoting drugs and their associations with night-shift work and health indices (excessive sleepiness, stress and burnout), performance (fatigue-related errors) and safety (near-crashes) outcomes. These outcomes were chosen given that they have previously been demonstrated to be negatively impacted by night shifts, ${ }^{24}$ and increases in these outcomes is likely to play a role in unintentional injuries and increased mortality in police officers. $^{16}$

\section{METHODS}

\section{Participants}

Police officers in North America (USA 97\%, Canada $3 \%$ ) were recruited to participate in a cross-sectional study either online $(n=3693)$ or onsite $(n=1264)$. A total of 4957 officers completed the survey between July 2005 and December 2007 with a cooperation rate of $63.1 \%$ in the onsite cohort and a $91.9 \%$ participation rate in the online sample. ${ }^{4}$ Further details of the sample have been described previously, ${ }^{4}$ and when completing the survey, all participants reported being 18 years or older and were sworn police officers.

Participants provided written or electronic informed consent and were not informed about study hypotheses.

\section{Materials and survey instruments}

In the survey, participants completed sections on their demographics (age, gender, primary role within the police force, length of service and ethnicity). Participants then answered questions about their sleep-promoting drug use (alcohol, prescription sleep medication, over-the-counter (OTC) or herbal medication, and medication that listed sleepiness as a side effect) and wake-promoting drug use (caffeine, cigarettes, prescribed medication and OTC/ herbal medication). Each of these drug use questions asked participants about their use of these types of drugs over the past month, with responses subsequently coded as 'used' or 'not used' in the past month.

The survey also contained questions about health, performance and safety outcomes over the past month. Stress was assessed with a Likert-type scale asking participants to rate their level of stress from 1 (not at all stressful) to 7 (very stressful) over the past month. The Maslach Burnout Inventory (sensitivity 0.70, specificity $0.57)^{17}$ is a 22-question, validated questionnaire. The emotional exhaustion subscale contains nine items and was used to assess burnout that develops in response to chronic occupational stress. ${ }^{18}$ Excessive sleepiness was assessed using the Epworth Sleepiness Scale (ESS) (sensitivity 0.94 , specificity 1.00). ${ }^{19}$ Performance was assessed with the questions, 'In the last month, do you believe sleep deprivation or fatigue caused you to make a mistake or be unnecessarily unsafe in some way?' and 'In the last month, do you believe you made a mistake or were unnecessarily unsafe in some way for reasons other than sleep deprivation or fatigue?' To assess motor vehicle safety following a shift, the following questions were used: 'In the last month, did you have any near miss motor vehicle 
accidents or crashes (narrowly avoided property damage or bodily harm) in which you were driving?', 'How likely are you to doze off...: While driving, after you worked a night shift?' and 'How likely are you to doze off...: While driving, after you worked a day or evening shift?' Night shifts were defined as having worked 3 or more $8-10$ hour shifts between 22:00 and 08:00 or 12-hour shifts between 19:00 and 09:00 in the last month.

\section{Data analyses}

$\chi^{2}$ analyses were used to compare police who had used versus those who had not used each sleep-promoting and wake-promoting drug on outcome variables in the past month. Outcomes considered were excessive daytime sleepiness (ESS scores exceeding 10); any near-miss crashes or dozing reported following a work shift, any errors made while at work and levels of stress (1-7 on Likert-type scale) and burnout (scores of 18+ reflecting moderate-high burnout). Binary logistic regression models were used to examine the increase (or decrease) in risk associated with use of sleep-promoting and wake-promoting medication and in their interaction with night-shift work. Binary logistic regression models were also used to asses risky use of the social drugs (caffeine, alcohol and smoking) as predicted by use of sleep-promoting and wake-promoting medication and night-shift work. For alcohol consumption, risky use was defined as exceeding $196 \mathrm{~g}$ in the past week in males (equivalent to 14 standard drinks) and $98 \mathrm{~g}$ per week in females (equivalent to seven standard drinks), with a standard drink containing $14 \mathrm{~g}$ of alcohol. Caffeine consumption was classified as 'High' (>400 mg of caffeine per day, equivalent to $\sim 5$ servings/day) or 'Low' ( $\leq 400 \mathrm{mg}$ per day, $\sim$ up to four servings) to reflect caffeine consumption in the US population. ${ }^{20}$ Smoking status was assessed in two ways. Smokers were compared with non-smokers, with this former group being divided into smokers who reported engaging in this behaviour to stay awake, compared with smokers who did not report smoking to stay awake. Statistical analyses were conducted using SPSS (V.21).

\section{Patient and public involvement}

This study used secondary data of an existing data source, hence patients and the general public were not involved in the development or design of the research.

\section{RESULTS}

\section{Sample characteristics}

A total of 4957 police officers ( $82 \%$ male), with a mean age of 38.5 years $(\mathrm{SD}=8.3)$ completed the survey.

\section{Drug use}

Table 1 shows sleep-promoting and wake-promoting drug use by police.

Sleep-promoting drug use was reported by approximately $20 \%$ of police officers in the past month. Regarding the use of wake-promoting drugs, caffeine use was almost
Table 1 Use of sleep-promoting and wake-promoting drugs and social drugs by police officers

\begin{tabular}{|c|c|}
\hline Drug/class & $\begin{array}{l}\text { Categorisation for analysis } \\
\text { (n, \% valid responses) }\end{array}$ \\
\hline \multirow{3}{*}{$\begin{array}{l}\text { Wake-promoting } \\
\text { drugs (excl. caffeine } \\
\text { and nicotine) }\end{array}$} & Used in the past month \\
\hline & Yes $(180,5.4 \%)$ \\
\hline & No $(3160,94.6 \%)$ \\
\hline \multirow{3}{*}{$\begin{array}{l}\text { Sleep-promoting } \\
\text { drugs }\end{array}$} & Used in the past month \\
\hline & Yes $(738,21.6 \%)$ \\
\hline & No $(2674,78.4 \%)$ \\
\hline \multirow{3}{*}{$\begin{array}{l}\text { Drugs with sleepiness } \\
\text { as a side effect }\end{array}$} & Used in the past month \\
\hline & Yes $(648,19.5 \%)$ \\
\hline & No $(2678,80.5 \%)$ \\
\hline \multirow[t]{3}{*}{ Alcohol } & Risky alcohol use* \\
\hline & Yes $(180,6.3 \%)$ \\
\hline & No $(2709,93.7 \%)$ \\
\hline \multirow[t]{4}{*}{ Caffeine } & Average consumption per day $\dagger$ \\
\hline & None $(366,10.7 \%)$ \\
\hline & Low $(2250,66.0 \%)$ \\
\hline & High $(793,23.3 \%)$ \\
\hline \multirow{4}{*}{$\begin{array}{l}\text { Nicotine } \\
\text { (cigarettes) }\end{array}$} & Smoking Status \\
\hline & $\begin{array}{l}\text { Smoked to stay awake ( } 149,4.2 \% \text { of } \\
\text { responses and } 27.2 \% \text { of smokers) }\end{array}$ \\
\hline & $\begin{array}{l}\text { Smoked but not to stay awake ( } 398 \text {, } \\
11.1 \% \text { of responses and } 72.8 \% \text { of } \\
\text { smokers) }\end{array}$ \\
\hline & $\begin{array}{l}\text { Non-smoker (3028, 84.7\% of } \\
\text { responses) }\end{array}$ \\
\hline
\end{tabular}

*USA limit for consumption: $196 \mathrm{~g} /$ week males (14 standard drinks) and $98 \mathrm{~g} /$ week females (seven standard drinks). A standard drink contains $14 \mathrm{~g}$ of alcohol.

†High $>400 \mathrm{mg}$ of caffeine per day (5+ servings/day); low $\leq 400 \mathrm{mg}$ per day (up to four servings). ${ }^{19}$

$\ddagger n=98(2.9 \%)$ of police officers reported use of a sleep-promoting/ drug with sleepiness as a side effect and a wake-promoting drug in the past month.

ubiquitous (approximately 90\% used caffeine in the past month). Furthermore, over one-quarter of police reported using either a wake-promoting drug, high levels of caffeine or smoked to stay awake. While only $8.9 \%$ of the sample had received a formal diagnosis of shift-work disorder by self-report, these officers were more likely to report using: sleep-promoting drugs, wake-promoting drugs, medication with sleepiness as a side effect or to report smoking to stay awake (all $\mathrm{p}<0.05$ ) in the past month.

\section{Adverse outcomes associated with drug use}

Figures 1 and 2 display adverse outcomes associated with use of sleep-promoting and wake-promoting drugs.

Sleep-promoting and wake-promoting drug use was associated with poorer outcomes on self-reported sleepiness, fatigue-related errors, drive performance following 


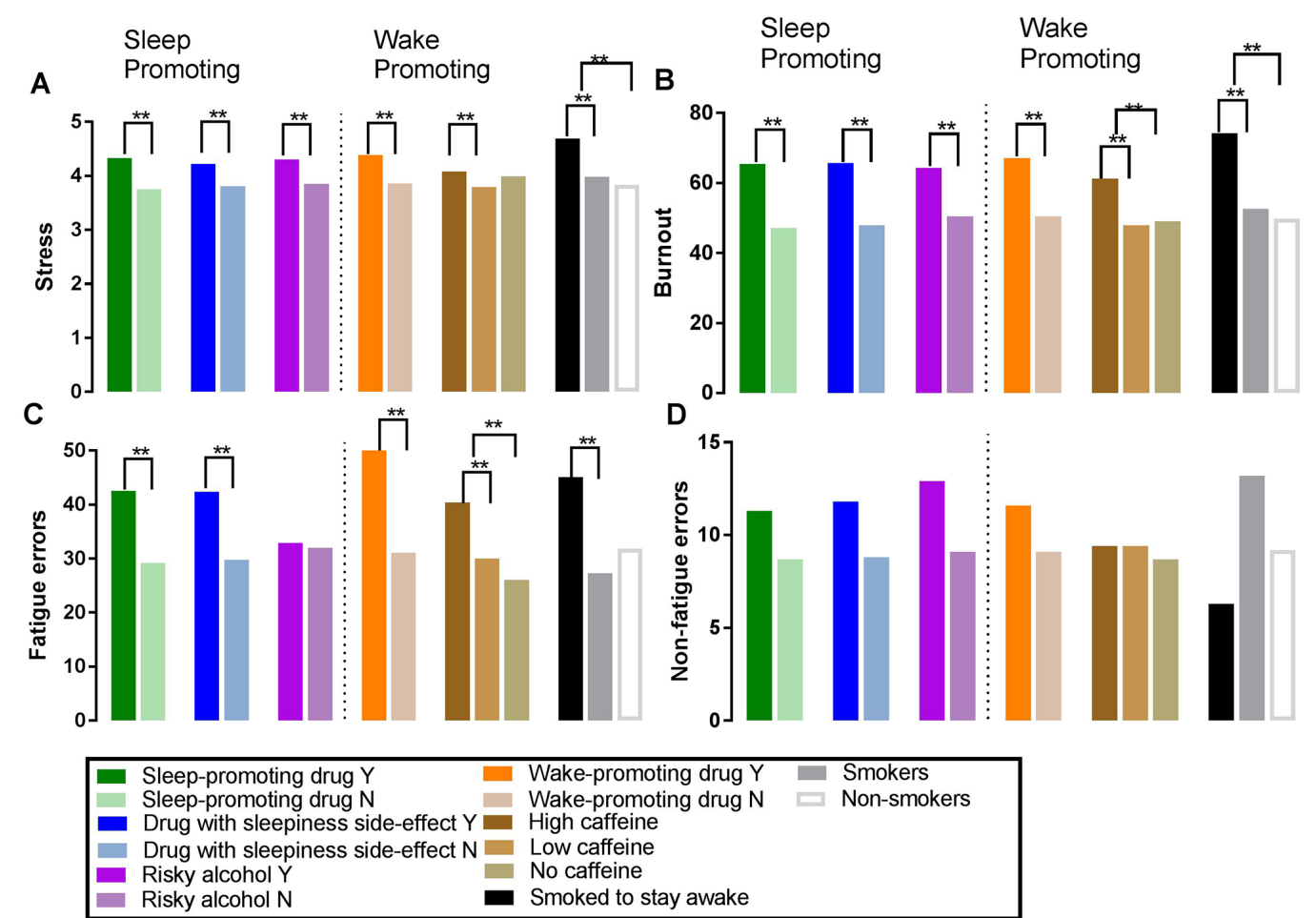

Figure 1 Proportion of police officers reporting stress (A), burnout (B), fatigue-related errors (C) or non-fatigue errors (D) by use of drug. ${ }^{*} \mathrm{P}<0.05,{ }^{\star \star} \mathrm{p}<0.01$.
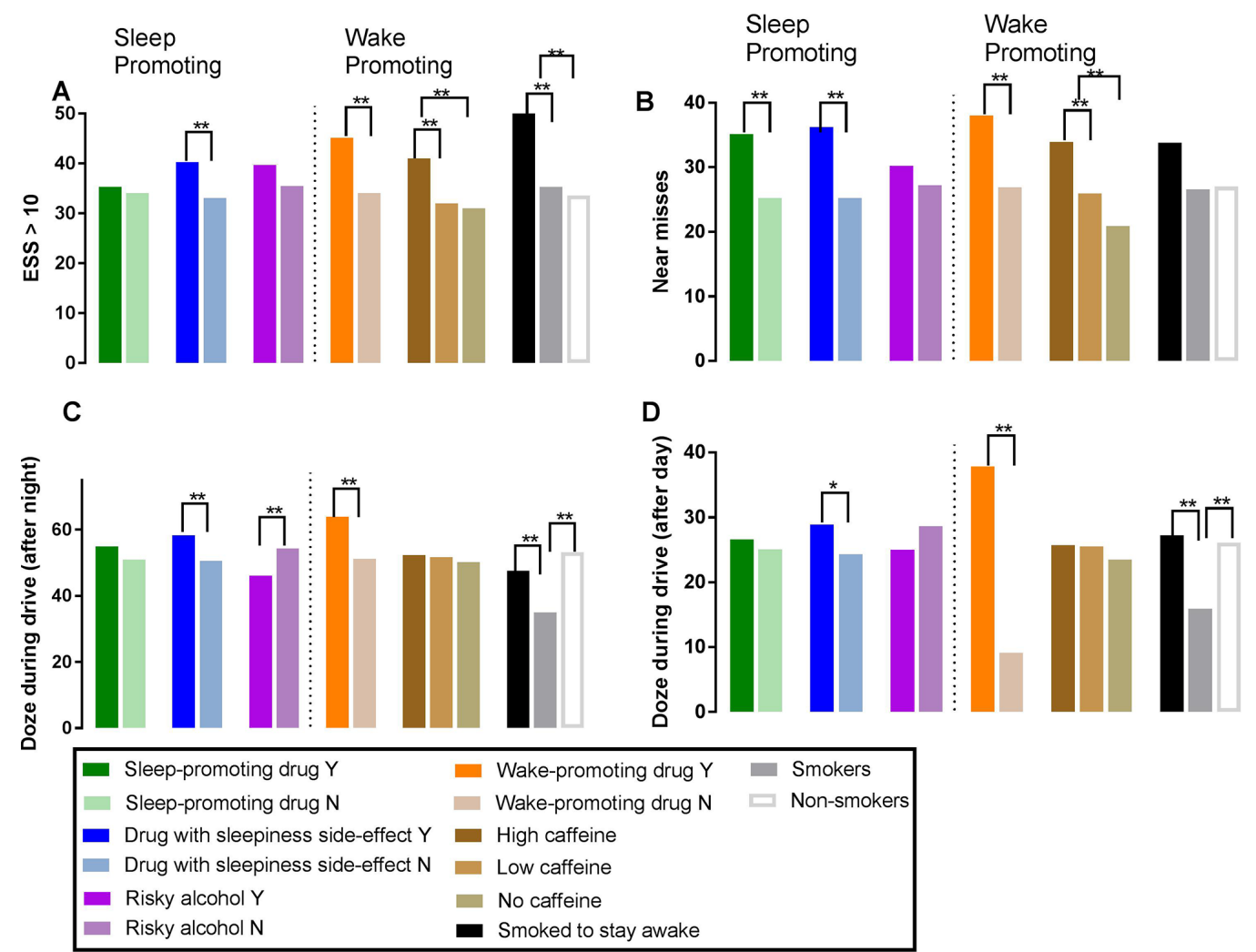

Figure 2 Proportion of police officers reporting excessive daytime sleepiness (A), near-misses (B), dozing during a drive following a night shift (C) or day-shift (D) by use of drug. ${ }^{\star} P<0.05,{ }^{\star \star} \mathrm{p}<0.01$. ESS, Epworth Sleepiness Scale.

a shift and increased levels of stress and burnout. In addition, those who smoked cigarettes to stay awake and high caffeine consumers reported poorer outcomes.
To better understand the risk of adverse outcomes associated with use of sleep-promoting and wake-promoting drugs and night shifts, binary logistic regression 
Table 2 Logistic regression models predicting study outcomes on sleepiness, near-crashes, fatigue-related work errors, stress and burnout

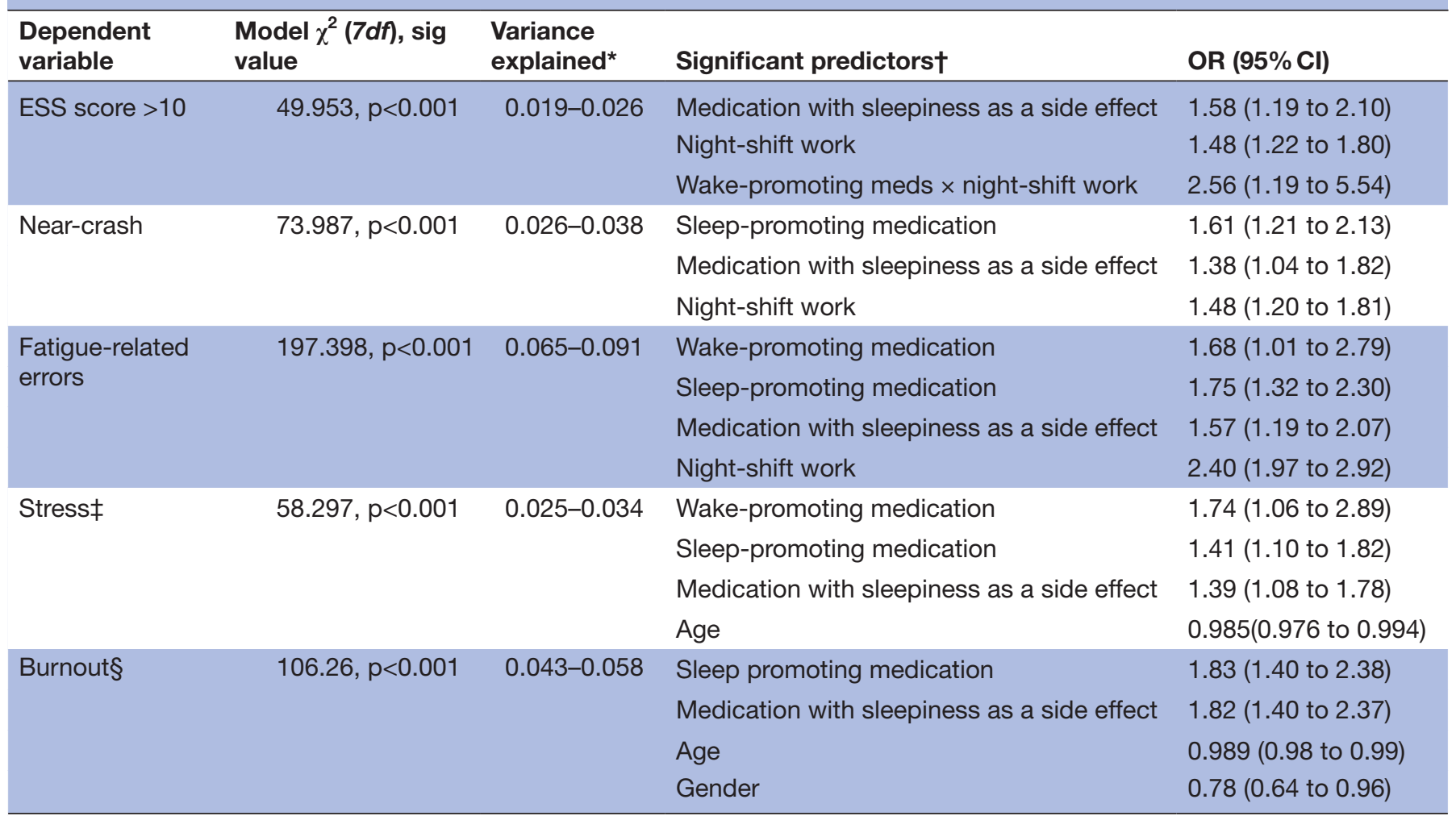

*Estimates here represent Cox \& Snell R-Square and Nagelkerke R-square values.

†Predictors and levels entered into the model: wake medications: used in the past month versus not used, sleep medications: used in the past month versus not used, medication with sleepiness as a side effect: used in the past month versus not used, night-shifts: worked versus not. Only variables significantly contributing to the model are included in the table. Model controlled for age and gender.

¥Scores of 5-7 on a seven-point Likert-type scale.

$\S$ Created using Maslach's burnout scale (emotional subscale) - scores of 18+ used to reflect moderate-high burnout.

ESS, Epworth Sleepiness Scale.

modelling was performed using the following outcome variables: excessive sleepiness, near-crashes, fatigue-related errors, stress and burnout (see table 2). We also conducted analysis controlling for previously diagnosed insomnia, obstructive sleep apnea (OSA), and shift work disorder (SWD), with findings indicating that use of sleep-promoting and wake-promoting drugs and nightshift work were still associated with increased risk of poorer outcomes (see online supplementary table 1).

Police using a sleep-promoting medication or a drug that listed sleepiness as a side effect in the past month were more likely to report a near-crash while driving (sleep promoting: OR=1.61, 95\% CI 1.21 to 2.13 , side effect: $\mathrm{OR}=1.38,95 \%$ CI 1.04 to 1.82 ), more likely to report a fatigue-related error (sleep promoting: $\mathrm{OR}=1.75,95 \%$ CI 1.32 to 2.30 , side effect: $\mathrm{OR}=1.57,95 \%$ CI 1.19 to 2.07 ) and higher levels of stress (sleep promoting: OR=1.41, 95\% CI 1.10 to 1.82 , side effect: $\mathrm{OR}=1.39,95 \%$ CI 1.08 to 1.78 ) or burnout (sleep promoting: OR=1.83, 95\% CI 1.40 to 2.38, side effect: $\mathrm{OR}=1.82,95 \%$ CI 1.40 to 2.37 ) compared with non-users. Wake-promoting medication use was associated with increased odds of a fatigue-related error $(\mathrm{OR}=1.68,95 \%$ CI 1.01 to 2.79$)$ and stress $(\mathrm{OR}=1.74$, $95 \%$ CI 1.06 to 2.89). Night-shift work was also associated with independent increases in risk for excessive sleepiness $(\mathrm{OR}=1.48,95 \%$ CI 1.22 to 1.80$)$, near-crash events $(\mathrm{OR}=1.48,95 \%$ CI 1.20 to 1.81$)$ and fatigue-related errors $(\mathrm{OR}=2.40,95 \%$ CI 1.97 to 2.92). Interactions between night-shift work and wake-promoting drug use were also found for excessive daytime sleepiness $(\mathrm{OR}=2.56,95 \% \mathrm{CI}$ 1.19 to 5.54$)$.

Binary logistic regression models were also used to assess risky use of alcohol, caffeine and those who smoked to stay awake, using sleep-medication and wake-medication use and night-shift work as predictors (see table 3 ).

Use of sleep-promoting medication ( $\mathrm{OR}=1.49,95 \%$ CI 1.12 to 1.98 ) and night-shift work (OR=1.42, 95\% CI 1.16 to 1.74) each independently was associated with increased excessive caffeine use and smoking in order to stay awake ( sleep promoting: OR=1.97, 95\% CI 1.06 to 3.64, night-shift work: $\mathrm{OR}=2.12,95 \%$ CI 1.34 to 3.36 ).

\section{DISCUSSION}

The present study identified night shifts as an independent risk factor for excessive daytime sleepiness, near-crashes and fatigue-related errors, supporting previous studies. ${ }^{2}{ }^{3}$ Importantly, the present study 
Table 3 Logistic regression models predicting risky use of social drugs

\begin{tabular}{|c|c|c|c|c|}
\hline Dependent variable & $\begin{array}{l}\text { Model } \chi^{2}(7 d f) \\
\text { sig value }\end{array}$ & $\begin{array}{l}\text { Variance } \\
\text { explained* }\end{array}$ & Significant predictors $†$ & OR $(95 \% \mathrm{Cl})$ \\
\hline \multirow[t]{3}{*}{ High caffeine } & \multirow[t]{3}{*}{$41.81, p<0.001$} & \multirow{3}{*}{$\begin{array}{l}0.017- \\
0.026\end{array}$} & Sleep-promoting medication & 1.49 (1.12 to 1.98$)$ \\
\hline & & & Gender & $1.29(1.02$ to 1.63$)$ \\
\hline & & & Age & $1.02(1.01$ to 1.03$)$ \\
\hline $\begin{array}{l}\text { Smokers who smoke to } \\
\text { stay awake§ }\end{array}$ & $23.759, p=0.001$ & $\begin{array}{l}0.008- \\
0.028\end{array}$ & Night-shift work & $2.12(1.34$ to 3.36$)$ \\
\hline
\end{tabular}

*Estimates here represent Cox \& Snell R-Square and Nagelkerke R-square values.

†Predictors and levels entered into the model: wake medications: used in the past month versus not used, sleep medications: used in the past month versus not used, medication with sleepiness as a side effect: used in the past month versus not used, night shifts: worked versus not. Only variables significantly contributing to the model are included in the table. Model controlled for age and gender.

fUsers who exceeded NIH/NIAAA limits for past week use.

$\S S$ mokers who reported engaging in this behaviour in order to remain alert.

extends this work by showing that use of sleep-promoting and wake-promoting drugs was independently associated with poorer health (eg, stress and burnout) and performance (eg, fatigue attributable errors and near-crashes) outcomes. Use of sleep-promoting and wake-promoting drugs was also associated with increased excessive sleepiness in night-shift workers. Relationships between drug use and poor outcomes remained significant even after controlling for common sleep disorders.

One-in-five police officers reported using a sleep-promoting drug or drug that listed sleepiness as a side effect. While we did not ask police officers about their use of specific classes of sleep-promoting medication, the use of benzodiapines is common in the USA, with a retrospective study reporting that 1-in-20 adults had been prescribed a drug from this class during $2008,{ }^{21}$ suggesting higher rates of use of sleep-promoting drugs in this group. While short-term use of medications including benzodiazepines is recommended to ameliorate insomnia, benzodiazepine use has been associated with impairment of driving performance, ${ }^{22}$ with a single dose of lorazepam causing greater lane deviations compared with alcohol intoxication of $0.05 \%$ blood alcohol concentration $(\mathrm{BAC}){ }^{23} \mathrm{In}$ addition, triazolam causes residual next-day decrements in driving performance, ${ }^{24}$ and benzodiazepines with a long half-life commonly prescribed as anxiolytics, have also been associated with increased risk of a motor crash. ${ }^{22}$ This is important given the increased rates of stress and burnout reported by police who used sleep-promoting medication in the present study, and previously reported decreases in quality of life and depression symptoms in nurses reported to have used hypnotic drugs. ${ }^{25}$ Police using sleep-promoting medication were also more likely to report an error at work attributable to fatigue. Procedural errors and injuries at work associated with use of hypnotic drugs have also been reported in nurses. ${ }^{25}$ Such effects may result from a desire to overcome sleepiness or anxiety (given the ESS and high stress reported by police in this sample) or reflect rebound or next-day effects.
Caffeine is widely consumed across the population, with $89 \%$ of adults in the USA consuming caffeinated beverages, ${ }^{26}$ similar to the distribution of use reported in our study. However, while mean average consumption is estimated at $186 \mathrm{mg}$ across the population, ${ }^{26}$ we found that more than $20 \%$ of police used a high level of caffeine $(>400 \mathrm{mg} /$ day), and more than $5 \%$ used a medication or OTC drug to promote wakefulness (excluding caffeine) in the past month. Lifetime prevalence of wake-promoting drugs differs across the population, but student samples have estimated a lifetime prevalence of $2 \%-8 \%$ depending on drug class, broadly similar to use in the present study. ${ }^{27}$ Of those who smoked, a third reported doing so to remain awake. Wake-promoting agents may be used by shift-workers in order to maintain vigilance and alertness on shift; however, evidence on their efficacy is mixed. ${ }^{15}$ Previous studies have suggested that modafinil may have cognitive enhancing effects following sleep deprivation, including in those engaged in simulated night-shift work. ${ }^{28}$ Other reports have suggested increases in some measures of simulated driving performance, specifically lane deviation but not speed deviation or off-road incidents, following modafinil suggesting caution with its use as a countermeasure for sleepiness. ${ }^{29}$ Our logistic regression analysis did not find wake-promoting drug use a significant predictor of near-crashes. This may reflect that these drugs are being used to alleviate tiredness prior to driving a vehicle, or alternatively, if there is a negative impact on driving performance as found in the studies above, that a much smaller proportion of police officers were using wake-promoting drugs $(\sim 5.4 \%)$ compared with sleep-promoting drugs $(\sim 20 \%)$. Our study found that use of wake-promoting drugs was associated with reported decrements in performance, and also increased levels of stress/burnout that may be related to changes in shift schedule, particularly given the interaction between use of wake-promoting medication and night-shift work that significantly increases the odds of excessive levels of daytime sleepiness. Given this pattern 
of findings, future research should investigate both the time of day and intention for use of wake-promoting drugs to determine whether they are being used to aid work-related tasks specifically at work and/or driving, and whether there are pharmacokinetic consequences to this timing, which may impact subsequent behaviours.

Widespread use of licit stimulants was common among police in our sample, and moderate caffeine consumption (eg, up to $250 \mathrm{mg}$ ) has been proposed as a countermeasure to increase performance during night-shift work by the National Sleep Foundation. ${ }^{30}$ Dependence on caffeine has been associated with negative consequences, however, including poorer sleep quality and increased daytime dysfunction. ${ }^{14}$ In our study, high caffeine users $(>400 \mathrm{mg})^{20}$ were more likely to report a fatigue-related error or near-miss crash in the present study. These findings are consistent with a previous report that caffeine is the most prevalent stimulant in fatal-to-the-driver heavy truck crashes. ${ }^{31}$ While use of caffeine in moderate levels may protect against sleepiness-related errors at work, exceeding these levels is associated with detrimental health and performance impacts. Our results suggest that high caffeine use may be an important marker of vulnerability to excessive sleepiness and performance impairment.

Although the majority of police in our sample were non-smokers, of those who smoked, almost one in three reported smoking in order to stay awake. Smoking rates are reportedly higher in night-shift workers, with rates of uptake that are significantly greater in shift workers compared with traditional day workers. ${ }^{32}$ Indeed, lung cancer rates of rotating shift workers are significantly greater in current smokers. ${ }^{33}$ In addition, dependence on nicotine has been associated with numerous adverse health effects, including poorer sleep. ${ }^{14}$ Police in our sample who reported smoking in order to remain awake reported greater levels of daytime sleepiness, increased propensity to make fatigue-related errors and higher levels of stress and burnout, even compared with smokers who did not engage in this behaviour. As was the case with those officers reporting high caffeine consumption, it may be that these users are vulnerable to the effects of shift work and are using high levels of these stimulants as a countermeasure against this vulnerability. This may at least in part explain the previous finding that smoking rates are higher in night-shift workers compared with day workers. $^{32}$

Recent work has called for further research to understand the interindividual variability in sleep-wake responses to shift work in order to identify those vulnerable or resilient to assist them in managing shifts. ${ }^{6}$ The present study suggests that excessive use of sleep-promoting or wake-promoting medication may be one such trait, given higher rates of use in those formally diagnosed with shift-work disorder. Our models found that both night-shift work and use of sleep-promoting medication were associated with increased odds of both high caffeine use and smoking to stay awake, with high use of each of these drugs associated with adverse health and safety outcomes. In addition to organisational efforts to promote shift-work schedules associated with better health and safety outcomes, ${ }^{2}$ individual differences in the vulnerability to sleepiness caused by shift work should also be considered, recognising that excessive use of pharmacological countermeasures should not be considered the first-line management approach in such cases. A possible approach to assess the extent of sleepiness in shift work, and the role that stimulants including licit and available ones play in enabling shift-work or extended duration work shifts, is to raise the hypothetical question: what would happen to workplace sleepiness, safety and productivity if caffeine use was not permitted?

\section{Limitations and future research}

The present study used self-assessment of the primary health and performance outcomes and may be subject to a bias not to report, given the consequences of errors associated with police work and the non-complete cooperation and response rates. Previous studies using both cross-sectional and prospective designs have reported similar levels of outcomes as reported here, however, including in occupational groups such as police where errors can have large negative impacts. ${ }^{4}$ The retrospective nature of the drug use questionnaires may have been affected by recall bias or a social desirability bias given the lower response rates to some of the drug use questions. In addition, we did not ask participants to nominate whether specific drug classes under the rubric of sleep promoting or wake promoting had been used, and future studies may use other methods to gauge drug use and/or behavioural outcomes using timeline follow back methods ${ }^{34}$ over longer periods to further examine the relationship between drug use, health, productivity and safety variables. Despite this, we still found significant associations between the use of sleep-promoting and wake-promoting drugs and health and performance outcomes. Future studies should incorporate amount and frequency estimates of drug and medication use, as well as eliciting more information about the time at which these drugs are used and specific drug classes used to better understand these associations. Collection of these additional data may also allow for further examination of the small subgroup of officers who reported use of both a sleep-promoting and a wake-promoting drug in the past month.

\section{Conclusion}

The present study found that over and above the effects of working night shifts, use of sleep-promoting and wake-promoting drugs was associated with detrimental health (stress, burnout and excessive daytime sleepiness), performance (errors) and safety (near-crashes) outcomes. In the past month, one in five police officers reported using a sleep-promoting drug, or drug that listed sleepiness as a side effect, and almost one in three used a wake promoting drug, high caffeine levels or 
smoking cigarettes to stay awake. Examining patterns of drug use among shift workers may provide useful markers of vulnerability to shift work to form the basis for personalised intervention strategies.

Contributors RPO, LKB, SWL, CS0, JPS, CAC and SMWR conceived the research question and study design. LKB, SWL, CAC and SMWR obtained funding for data collection. LKB, SWL, CSO, JPS, SQ, CAC and SMWR acquired the data. RPO, LKB, SWL, JPS, DIL, CAC and SMWR analysed and/or interpreted data from the study. RPO drafted the initial manuscript, with critical revision and important intellectual content provided by RPO, LKB, SWL, CSO, JPS, SQ, DIL, CAC and SMWR. Administrative, technical or material support was provided by CSO, JPS and SQ. Study supervision was provided by LKB, CSO, JPS, CAC and SMWR.

Funding This study was supported by grant 2004-FS-BX-0001 and grant 2010C-10002 from the National Institute of Justice, Office of Justice Programs, US Department of Justice; grants R01 $\mathrm{OH} 008496$ and R01 $\mathrm{OH} 009403$ from the Centers for Disease Control and Prevention. R0 was supported by a Harvard Club of Australia Fellowship and is the recipient on an NHMRC Peter Doherty award. LB was supported in part by grant R01 $\mathrm{OH} 010300$ from the National Institute of Occupational Safety and Health.

Competing interests LKB has consulted for Sygma, NASA Ames Research Center, Insight and CurAegis. She is on the scientific advisory board of CurAegis. SWL declares no conflicts with the work described herein. In the past 3 years, he has received consulting fees from the Atlanta Falcons, Atlanta Hawks, Consumer Sleep Solutions, OpTerra Energy Services Inc., Pegasus Capital Advisors LP, Serrado Capital, Slingshot Insights and Team C Racing and has current consulting contracts with Akili Interactive, Apex 2100 Ltd, Delos Living LLC, Headwaters Inc., Hintsa Performance AG, Light Cognitive, Lighting Science Group Corporation, Mental Workout, PlanLED, Six Senses and Wyle Integrated Science and Engineering. SWL has received unrestricted equipment gifts from Biological Illuminations LLC, Bionetics Corporation and F.Lux Software LLC; has equity in iSLEEP, Pty; advance author payment and/or royalties from 0xford University Press; honoraria plus travel, accommodation and/or meals for invited seminars, conference presentations or teaching from BHP Billiton, Lightfair, Informa Exhibitions (USGBC), Teague; and travel, accommodation and/or meals only (no honoraria) for invited seminars, conference presentations or teaching from DIN, FASEB, Lightfair, SLTBR and USGBC. SWL has completed an investigator-initiated research grant from Biological Illumination LLC and has an ongoing investigator-initiated grant from F. Lux Software LLC. SWL holds a process patent for 'Systems and methods for determining and/or controlling sleep quality', which is assigned to the Brigham and Women's Hospital per Hospital policy. SWL has also served as a paid expert for legal proceedings related to light, sleep and health. SWL is a Program Leader for the CRC for Alertness, Safety and Productivity, Australia. DIL has received speaking honoraria from AstraZeneca, Indivior, Janssen, Servier, Shire and Lundbeck and has provided consultancy advice to Lundbeck and Indivior. CAC has received consulting fees from or served as a paid member of scientific advisory boards for: Ganésco Inc.; Institute of Digital Media and Child Development; Klarman Family Foundation; Vanda Pharmaceuticals; and Washington State Board of Pilotage Commissioners. CAC has also received education/research support from Optum, Philips Respironics, Inc., San Francisco Bar Pilots, Schneider Inc., Sysco, Vanda Pharmaceuticals, Sanofil S.A., Regeneron Pharmaceuticals, Inc., and Jazz Pharmaceuticals plc. The Sleep and Health Education Program of the Harvard Medical School Division of Sleep Medicine and the Sleep Matters Initiative (which CAC directs) have received funding for educational activities from Cephalon, Inc., Jazz Pharmaceuticals, ResMed, Takeda Pharmaceuticals, Teva Pharmaceuticals Industries Ltd., Sanofi-Aventis, Inc., Sepracor, Inc., Wake Up Narcolepsy and Mary Ann \& Stanley Snider via Combined Jewish Philanthropies. CAC is the incumbent of an endowed professorship provided to Harvard University by Cephalon, Inc. and holds a number of process patents in the field of sleep/circadian rhythms (eg, photic resetting of the human circadian pacemaker). Since 1985, CAC has also served as an expert on various legal and technical cases related to sleep and/or circadian rhythms including those involving the following commercial entities: Complete General Construction Company, FedEx, Greyhound, HG Energy LLC, South Carolina Central Railroad Co., Steel Warehouse Inc., Stric-Lan Companies LLC, Texas Premier Resource LLC and United Parcel Service. CAC owns or owned an equity interest in Vanda Pharmaceuticals. He received royalties from McGraw Hill and Koninklijke Philips Electronics, N.V. for the Actiwatch-2 and Actiwatch-Spectrum devices, and has received royalties from the New England Journal of Medicine. CAC's interests were reviewed and managed by Brigham and Women's Hospital and Partners HealthCare in accordance with their conflict of interest policies. SMWR reports that he has served as a consultant through his institution to Vanda Pharmaceuticals, Philips Respironics, EdanSafe, The Australian Workers' Union, National Transport Commission, Transport Accident Commission, New South Wales Department of Education and Communities and has through his institution received research grants and/or unrestricted educational grants from Vanda Pharmaceuticals, Shell, Teva Pharmaceuticals, Rio Tinto, Seeing Machines, Takeda Pharmaceuticals North America, Philips Lighting, Philips Respironics, Cephalon and ResMed Foundation and reimbursements for conference travel expenses from Vanda Pharmaceuticals. His institution has received equipment donations or other support from Optalert, Compumedics and Tyco Healthcare. He has served as an expert witness and/or consultant to shift work organisations. SMWR also serves as a Program Leader in the Cooperative Research Centre for Alertness, Safety and Productivity.

\section{Patient consent Obtained.}

Ethics approval The protocol was approved by the Partners and Monash Human Research Ethics Committees, with the secondary analysis of data for the present analysis approved in April 2015.

Provenance and peer review Not commissioned; externally peer reviewed.

Data sharing statement The data that support the findings of this study are available from the authors upon reasonable request.

Open access This is an open access article distributed in accordance with the Creative Commons Attribution Non Commercial (CC BY-NC 4.0) license, which permits others to distribute, remix, adapt, build upon this work non-commercially, and license their derivative works on different terms, provided the original work is properly cited, appropriate credit is given, any changes made indicated, and the use is non-commercial. See: http://creativecommons.org/licenses/by-nc/4.0/.

\section{REFERENCES}

1. Institute of Medicine (US) Committee on Sleep Medicine and Research. Functional and economic impact of sleep loss and sleeprelated disorders. In: Colten HR, Altevogt BM, eds. Sleep disorders and sleep deprivation: an unmet public health problem. Washington DC, USA, 2006.

2. Drake CL, Roehrs T, Richardson G, et al. Shift work sleep disorder: prevalence and consequences beyond that of symptomatic day workers. Sleep 2004;27:1453-62.

3. Barger LK, Ogeil RP, Drake CL, et al. Validation of a questionnaire to screen for shift work disorder. Sleep 2012;35:1693-1703.

4. Rajaratnam SM, Barger LK, Lockley SW, et al. Sleep disorders, health, and safety in police officers. JAMA 2011;306:2567-78.

5. Czeisler CA, Johnson MP, Duffy JF, et al. Exposure to bright light and darkness to treat physiologic maladaptation to night work. $N$ Engl J Med 1990;322:1253-9.

6. Van Dongen HP. Shift work and inter-individual differences in sleep and sleepiness. Chronobiol Int 2006;23:1139-47.

7. Akerstedt T, Wright KP. Sleep loss and fatigue in shift work and shift work disorder. Sleep Med Clin 2009;4:257-71.

8. Kalmbach DA, Pillai V, Cheng P, et al. Shift work disorder, depression, and anxiety in the transition to rotating shifts: the role of sleep reactivity. Sleep Med 2015;16:1532-8.

9. Dorrian J, Heath G, Sargent C, et al. Alcohol use in shiftworkers. Accid Anal Prev 2017;99:395-400.

10. Dorrian J, Lamond N, van den Heuvel C, et al. A pilot study of the safety implications of Australian nurses' sleep and work hours. Chronobiol Int 2006;23:1149-63.

11. Schuckit MA. Alcohol-use disorders. Lancet 2009;373:492-501.

12. Room R, Babor T, Rehm J. Alcohol and public health. Lancet 2005;365:519-30.

13. Roche AM, Pidd K, Berry JG, et al. Workers' drinking patterns: the impact on absenteeism in the Australian work-place. Addiction 2008;103:738-48.

14. Ogeil RP, Phillips JG. Commonly used stimulants: sleep problems, dependence and psychological distress. Drug Alcohol Depend 2015;153:145-51.

15. Liira J, Verbeek JH, Costa G, et al. Pharmacological interventions for sleepiness and sleep disturbances caused by shift work. Cochrane Database Syst Rev 2014;8:CD009776.

16. Vila B. Impact of long work hours on police officers and the communities they serve. Am J Ind Med 2006;49:972-80.

17. Schaufeli WB, Bakker AB, Hoogduin $K$, et al. On the clinical validity of the maslach burnout inventory and the burnout measure. Psychol Health 2001;16:565-82.

18. Maslach C, Jackson SE, Leiter MP. Maslach burnout inventory manual. 3rd ed. Palo Alto CA: Consulting Psychologists Press, 1996. 
19. Johns MW. Sensitivity and specificity of the multiple sleep latency test (MSLT), the maintenance of wakefulness test and the epworth sleepiness scale: failure of the MSLT as a gold standard. J Sleep Res 2000;9:5-11.

20. Mitchell DC, Knight CA, Hockenberry J, et al. Beverage caffeine intakes in the U.S. Food Chem Toxicol 2014;63:136-42.

21. Olfson M, King M, Schoenbaum M. Benzodiazepine use in the United States. JAMA Psychiatry 2015;72:136-42.

22. Barbone F, McMahon AD, Davey PG, et al. Association of road-traffic accidents with benzodiazepine use. Lancet 1998;352:1331-6.

23. Daurat $A$, Sagaspe $P$, Moták $L$, et al. Lorazepam impairs highway driving performance more than heavy alcohol consumption. Accid Anal Prev 2013;60:31-4.

24. Kay GG, Schwartz HI, Wingertzahn MA, et al. Next-day residual effects of gabapentin, diphenhydramine, and triazolam on simulated driving performance in healthy volunteers: a phase 3 , randomized, double-blind, placebo-controlled, crossover trial. Hum Psychopharmacol 2016;31:217-26.

25. Futenma K, Asaoka S, Takaesu Y, et al. Impact of hypnotics use on daytime function and factors associated with usage by female shift work nurses. Sleep Med 2015;16:604-11.

26. Fulgoni VL, Keast DR, Lieberman HR. Trends in intake and sources of caffeine in the diets of US adults: 2001-2010. Am J Clin Nutr 2015;101:1081-7.
27. Singh I, Bard I, Jackson J. Robust resilience and substantial interest: a survey of pharmacological cognitive enhancement among university students in the UK and Ireland. PLoS One 2014:9:e105969.

28. Walsh JK, Randazzo AC, Stone KL, et al. Modafinil improves alertness, vigilance, and executive function during simulated night shifts. Sleep 2004;27:434-9.

29. Gurtman CG, Broadbear JH, Redman JR. Effects of modafinil on simulator driving and self-assessment of driving following sleep deprivation. Hum Psychopharmacol 2008;23:681-92.

30. Schwartz JRL, Roth T. Shift work sleep disorder. Drugs 2006;66:2357-70.

31. National Transportation Safety Board (NTSB). Safety study: fatigue, alcohol, other drugs, and medical factors in fatal-to-the-driver heavy truck crashes (volume 1). Washington DC: National Transportation Safety Board, 1990.

32. van Amelsvoort LG, Jansen NW, Kant I. Smoking among shift workers: more than a confounding factor. Chronobiol Int 2006;23:1105-13.

33. Schernhammer ES, Feskanich D, Liang G, et al. Rotating night-shift work and lung cancer risk among female nurses in the United States. Am J Epidemiol 2013;178:1434-41.

34. Pedersen ER, Grow J, Duncan S, et al. Concurrent validity of an online version of the timeline followback assessment. Psychol Addict Behav 2012;26:672-7. 